\title{
Online Advertising Effectiveness for Advertiser and User
}

\author{
$1^{\mathrm{st*}}$ Mentari Anugrah Imsa \\ Communication Management \\ Universitas Indonesia \\ Jakata, Indonesia \\ mentarianugrahimsa@gmail.com
}

\author{
$2^{\text {nd }}$ Irwansyah \\ Communication Management \\ Universitas Indonesia \\ Jakata, Indonesia \\ dr.irwansyah.ma@gmail.com
}

\begin{abstract}
The development of technology in industry 3.0 which was marked by the emergence of internet innovation in the 1980s has changed many practices in the industries, include advertising practice. Data showed that Internet User in Indonesia increased in line with the increase in advertising spending. Therefore, it is interesting to discuss online advertising and its effectiveness for advertisers and consumers. The aims of this paper are to provide a review and understand much deeper regarding concept of online advertising and its effectiveness from consumers and advertiser's point of view. The paradigm that is used in this study is the constructivist paradigm. The approach used on this study is a qualitative approach. This study used the meta-analysis method. This study also used secondary data obtained from several official web institutions. The data showed that there was an escalation on internet users in Indonesia and on digital advertising spending in 2006 to 2007. This shows an opportunity for advertisers to practice online advertising. This paper found several factors that could increase the effectiveness of online advertising so that it can bring up click action from internet users. The combination of the right size, the right message content, and interesting forms of advertising are concluded to increase the effectiveness of online advertising in generating click-through and awareness of internet users. Size of online ads that are not too large, appropriate short messages and does not attack the user's life values, will be more effective in attracting users to click on ad.
\end{abstract}

Keywords- online advertising, click-through-rate, effectiveness, consumer, advertiser

\section{INTRODUCTION}

The development of technology from analog to digital, occurred in the Industry 3.0, has an impact on many industries in the world. Industry 3.0 is marked by the emerging of the internet [1]. Internet has changed many practices, one of which was the practice of advertising. Advertising is defined as a form of controlled communication that tries to persuade consumers to buy or use certain products and services with various strategies [2]. The internet enhances a new strategy to advertise product/service in online advertising. Online advertising as known as internet advertising is a form of marketing communication which is done through internet channels and mobile devices [3]. Online advertising is more interesting for advertiser since its advantage for minimizing the marketing budget [3]. Online advertising enables advertiser to expand their target market [4]. The increasing of internet users in Indonesia is attracting company to advertise their product/service on Internet.
Internet users have increased from 2016 to 2017. Data from the Indonesian Internet Service Providers Association (APJII) obtained that in 2017 it contained 143.26 million of 261.9 million population or according to 54.7 percent of total population [5]. The escalation of the Internet users impacts the escalation in digital advertising spending in Indonesia. Data from Nielsen quoted from JakartaKita.com [6] showed that digital advertising spending in August 2018 in Indonesia reached $\mathrm{Rp} 1.3$ trillion. This data was obtained by Nielsen by monitoring 200 sites using Digital Ad Intel research [6]. The data that was collected also showed that of the total number of digital advertisements, 5 out of 10 are advertisements served on desktops, laptops, or computers and the remaining are advertisements on mobile devices. There are two forms of advertisements that are displayed, namely digital ads that are only display (display) and video where display form ads are used more than videos. E-Marketers predict the amount of online shopping in Indonesia will increase in the coming years [7].

Online advertising is being important and interesting to be understood since the rapid development of digital channel and the amount of internet users. It is also being important remembering nowadays people use more than one screen devices that may be consist of mobile device, personal computer, or television in one time to perform their task. Online advertising gives opportunity to expand the market. On the consumer's perspective, online advertising gives opportunity to directly interact with the company. Therefore, this study aims to explore understanding of online advertising and its effectiveness both from consumers and advertiser's point of view.

\section{LITERATURE REVIEW}

Online advertising or also being known as internet advertising is a method that being used with company to convey ad message to their customers through internet and mobile devices without geographic boundaries [3]. Online advertising is considered can attract new customers, expand the range of advertisement and increase the income [3]. Online advertising is defined as internet using activity as a media and communication channel for download ad on website [8]. Online advertising is a medium for advertise to communicate, to interact, and to persuade internet users in order to place the brand that enable company to increase awareness and preference of consumer [4]. Another definition of online advertising said that $\mathrm{OA}$ is form of commercial content that exist on the internet, that sent using various channels, and designed to inform consumers about product/service 
information on various level of depth [9]. Therefore, online advertising is a communication to convey their persuasive message regarding products and service that is spread using platform on the internet without geographic boundaries. Online advertising has two main functions, providing information and persuading. Providing information function refers to establishing consumer awareness and persuading function refers to attempt to rise positive attitude and behavior towards product/service[10].

Online advertising appeared in 1994 by HotWired, Web based magazine that sold advertising banner to AT\&T and displayed the ad on magazine web page [11]. The advertisement had been sold based on the number of users that see the ad known as "cost per mille" (CPM) which the ad was sold for each 1000 people who seen the ad. Furthermore, selling system amended to be "cost per click" (CPC) when Procter \& Gamble did negotiation with Yahoo! in 1996. The amendment occurred because on the CPM selling system, search engine website has crash between having to help people find somethings quickly and keeping user to see the ad [11].

Types of Online Advertising:

\section{1) Display Ads}

Display Ads or known as Banner Ads is graphic display include texts that involved rich media such as animation, audio, and video on a website page which will be directed user to advertiser website if they clicked it [12]. Display ads would be more effective when performed on proper behavioural targeting and demographic. Behavioural targeting refers to a technic that utilizes online behaviour in the past as the target for advertiser to convey the display ad [12]. Online behaviour is obtained from cookies, log files and other online data [12].

\section{2) Search Ads}

Search ads is appeared base on keywords that been used by user on search engine such as Google or Yahoo! [12]. Search Ads adjust search engine optimization where a web page would be on the top of list when user search keywords on search engine [12]. Website which want to be the top of list should design their page with content related to keyword that usually used or searched by users. Data of keywords could be obtained by software called "spider" or "crawlers" from search engine such as Google or Yahoo! [12].

\section{3) Dynamic retargeted ads}

Dynamic retargeted ads is an attempt to retarget their customers by seeing their search history on company website [13]. The company will review data browsing history from consumers on their website. Moreover, company will display an ad with recommendation or bringing up the similar product that have been searched by consumers previously on other websites while browsing [13].

\section{4) Pop-Ups ads}

Pop-Ups ads refers to ad on rich media that appear automatically on their new tab when a web page is being proceed [14]. A Pop up ad is a small window that will appear on the page browser, consist of texts, graphic, and other information that designed to maximize the effectiveness of ads. Small window could pop up while users enter the sites and even when leave the sites. Pop up ads is considered as the one of online advertising that could make users feel disturbed [15]. Pop up ads has two subset : floating advertisements and pop up advertisement [16]. Floating advertisements appears in front of the web page when user switch to another webpage and user have to wait before the ad disappears. Pop up ad will opens automatically on the new window when the destination webpage is processing to open. Users have to open or click other side to go to the destination webpage and make the ad disappear [16].

\section{5) Online behavioural advertising}

Online behavioural Advertising (OBA) is a practice in order to monitor people online behaviour and use collected information to determine people that will be see the targeted ad [17]. Online behaviour consist of web browsing data, search history, media consumption data (e.g. seen video), application using data, purchasing data, click through respond towards ad and communication content or uploaded content on social network [17].

\section{6) Coupon/Loyalty advertising (CLA)}

CLA is ad that aims to stimulate purchasing behaviour on consumer in a way by providing rewards for consumers that doing registration on programs (e.g. collecting points) or giving discount (e.g. discount $5 \%$ for second purchasing) [18]. The promotion is notified by banners CLA that show the coupon code when consumers click the banner. CLA is the effective way to escalate consumer's Loyalty towards high competitive product. Coupon/Loyalty Advertising is suitable to attract new customers [18].

\section{7) Search Engine Marketing (SEM)}

SEM bring the ad up on search engine such as Google and Yahoo!. Search engine gives sharp escalation on target that is activated by entered keywords by users on it [19]. When users enter a keyword on search engine, the ad that related to keyword will be displayed [19]. Search engine marketing involves several actions : keyword-related banner advertisements, paid submission/paid listing dan paid inclusion for regular updates, search engine optimization, dan paid placement [20]. Keyword-related banner refers to keyword ad buying on searching result page.

Hereafter, paid submission regarding payment towards search engine to ensure that advertisement website is seen on frame of time that has been determined (rate for a week) and appear on search result page [20]. Search Engine Optimization is related to escalation list result page studied by modifying codes sites in order to adjust it to search engine. Modification could be done on title tag, meta-tags, heading tags, links and on other areas on page to ensure search engine algorithm gives high scores for ad web page that other pages. Paid placements relates to payment that is done by advertiser to search engine for placement on sponsored section on search result page [20].

\section{8) Price comparison advertising}

Price comparison advertising is an internet service platform that enable users to compare price among various choices from seller. When the price is shown, there would be a link that direct the users to seller website and the click done by users is counted as effectiveness. PCA is a type of ondemand advertising [19].

\section{9) Online video advertisement}

Online video advertisement is a video content which spread through internet to being seen or downloaded on computer or mobile phone [21]. Online video advertisement is divided into several types : embedded video, in-text video, 
email video, and in-game video. Embedded video is ad video that adhere to certain web page and could be lured by click on banner from user. Subsite is an online video advertisement that open on different browser and start to play automatically when users close the website. Moreover, in-text video is ad that is sent when users swing to highlight word on webpage. Email video is ad video that embed on an email and could be sent to users when open email texts or click the banner on email. The last type is on-game video, it refers to video ad which is sent when the game is being played or when the level changes [21].

According their way to convey the online video advertisement, it could be divided into two categories. First category is linier video advertisements that refers to video with duration 15 to 30 seconds that has been played since the beginning, middle to end of the video. This video could not be accelerated. Moreover, the second category is interactive video advertisements that enable several interactions. Users could click the video for further information regarding location took, contact took or subscribe for newspaper on the video. Users could choose what ad that would like to see and when to see. Certain video advertisements have choice to skip the video [21].

Several websites have online advertising as the main income. Certain websites even display multiple ad on their website [22]. Online advertising industry has rapid development in size, significance, and complexity. Several businessmen have goal to use automation and data driven optimization on set marketing budget plan. Optimization refers to obstacles that is being faced advertiser that appear from interaction display ad with the users [23]. Therefore, feedback control from user is important on online advertising. Digital advertising agency is accused to understand digital ecosystem since the ad must have high diversity suitable with spectrum of the platform. Agency could make creative idea that suitable with each platforms [24]. Web based sellers use online advertising to attract consumers to visit the official websites of seller where consumers could search products and services and purchase with some clicks on the web [11].

\section{RESEARCH METHOD}

The paradigm used in this study is the constructivist paradigm. The constructivist paradigm is research that aims to understand more about human research and considers reality to be a social construction [25]. The research paradigm becomes a systematic investigation or determinant of answers for questions about research data collected, how the data is analyzed and interpreted in several ways with attempts to understand, predict, predict and control phenomena that can educate [25]. The research approach used is a qualitative approach. Qualitative related to research where data collected through words, images and icons are analyzed using thematic exploration [25]. This research uses a meta-analysis method. The meta-analysis is a design used to collect the results of several independent studies on specific objects [26]. This study also uses secondary data obtained from official web representatives.

\section{RESULT AND DISCUSSION}

Online advertising gives interactive feature for seller and consumers. Interactivity is considered by seller as one of the reasons for using online advertising. It enables both parties to give feedback for each other. On the contrary, conventional ad just occur one-way communication from advertiser to consumers and there is no feedback from consumers. The Internet amended the flow of communication to be two ways. Consumers could give direct feedback by complaining or indirect feedback by their search history data that is utilized by the advertiser to increase the target market with more variation. Consumers also obtain feedback in the form of specific information for needs from previously given feedback [27]. Interactivity on online advertising refers to a computer characteristic that is being a media for communication on the market that escalates two-way relationships in real-time, allow to control each other and give respond to received communication previously for consumers and advertiser [28].

\section{A. Online Advertising Effectiveness for Advertiser}

Online advertising solves one of the troubles faced by the advertising industry. It is the desire to send various messages to massive consumers. The advertiser is able to target their message to specific consumers that are suitable to receive their message and have big opportunities to purchase after has seen the message. That specific target market is obtained from IP addresses from internet users. This data provides valued details about the individual user such as location, habit pattern, and could track previous website that has been visited [11]. Online advertising offers significant economic effectiveness. It could be seen that online advertising minimize the budget for content making in order to reach the target and select the potential customers.

Online advertising effectiveness is also seen by the percentage of the total amount of exposure that causes the surface on the banner is responded by clicking on an ad message [29]. The measurement of that effectiveness is known as the click-through rate. The advertiser predicts CTR to increase online ad effectiveness that would be conveyed to consumers/internet users. Predicting process of CTR is divided into 4 steps [30]. The first step is feature extraction and followed by second step, model building. The third step is model training and the last step is model estimation [30]. However, low CRT could not be the determinant of online advertising effectiveness [29]. CTR just gives short term measurement for online advertising effectiveness. Ad repetition could affect longer or long term effects in the form of brand awareness or message awareness on ad.

CTR is also considered as a payment method of online advertising that implemented by a web site that offers advertisement space. There is another method on rate payment on online advertising, it is pay-per-action model [31]. The system of this model occurs on three parties, publisher as Google or Yahoo!, advertiser, and internet users. This method starts when the advertiser asks the wanted web page to the publisher. Furthermore, the publisher will display the ad on that web page. The internet users will do action besides clickthrough, such as fill the form on the advertiser's website, register as members of the website or purchase products from the advertiser's website. Those actions will be considered as the price on online advertising. Action refers to the responses from users that could not be controlled by publisher [31].

If we have discussed about effectiveness measurements of the ad, it is also important to discuss about factors that affect escalation or deflation of ad effectiveness. Ad frequency has effect towards effectiveness of online ad 
[29]. The study revealed that repetition has important effect towards online advertising effectiveness [29]. Repetition ad affected the memory about the ad, acquaint the brand, and brand awareness. Several studies revealed that banner size has effect towards online advertising. The bigger online ad size, more effective the ad through click-through by users [32]. The research also discovered the shorter the message of ad the more affective the ad. This is different with result from another study that discovered banners size did not has effect on online advertising effectiveness that measured by memory of ad, brand recognizing, and brand awareness [29]. Therefore, the advertiser should be more creative when designing the message in concise way. Combination of position and type of ad and animation duration are important for online advertising effectiveness. It could be used to evaluate animated online advertising [33]. The Web page with video and image-based will attract more attention for ad than on text-based web page. Research from The first page on the web is the best page to display advertisement so that it will raise the attention of the internet users even on text-based web page [34].

Content in the form of animation and banner affect the effectiveness of online advertising, although on small size. Another study has also found that animated content did not have a significant effect on direct responses from users [32]. Banner with animated content spends more budget in production and obtains negative responses from users. Creativity of advertising content is not effective in online advertising in case to generating direct user responses [32]. The delivered content also influences the effectiveness of online advertising where "what" is conveyed by advertisements is more important than "how" is it delivered. Another study discovered that online ad in the form of banner ad displayed on websites must be compatible with the website. If the displayed ad does not match the website, the user's attitude towards the website will tend to be low [35]. The relevant advertisements are more interesting and useful to users such as consumers considering that they are worthy of attention [36].

There are several things that advertiser could do in order to deliver advertisements effectively [37]. The Advertiser could create ad placement strategies to reduce feelings of disturbing from consumers / users. Users sometimes feel disturbed by ad that come abruptly on the web page that are being opened. Feeling disturbed by unexpected ad could be reduced in several ways. The first way is to target the users when have a low cognitive process or not in the thinking state that requires high focus. Ad could be displayed when there is a gap among contents on the web page. When users switch the web pages, there is a gap or free time among the contents. The blank time is the right time to bring the online advertising up. The second way is to increase the suitability of ad by using content placement strategies. When a user is browsing the web with car issue, it will be appropriate for car ad to appear on the web. Another example might be when a user is opening the web with fashion issue, then ad for clothes, pants and shoes will be appropriate to be displayed. This is inline with research from Hsieh and Chen (2011) who found that pages with information that is different from the sought content by internet users will attract more attention [34]. The third way is to provide values to users. Advertising could be considered as valuable ad when it provides information, interest and entertainment for users [14]. The fourth way is the content that matches the website in line with research from Peng et al. (2014) who found that the advertiser that allocate funds to search advertising will increase product sales. This happens because of the suitability of the web content with the sought keywords [38].

Online advertising has a long-term effect on sales. Search engine marketing has a longer effect than banners ad and coupon/loyalty advertising and price comparison advertising [19]. A meta-analysis study conducted by Hollis (2005) found that an exposure of online advertising has an influence on purchasing considerations [37]. Increased consideration shows that someone at least found a suitable brand for their needs and was worth checking. Hollis (2005) also explained how online advertising could influence brand consideration. When someone is exposed to online advertising at least someone remembers that they have seen an ad. This is called advertising awareness or awareness of advertising. Furthermore, this awareness will demand brand consideration. It could be seen that advertisements have to be made as well as possible in order to make an impression for internet users and will arise the advertising awareness. However the conveyed impression is in positive way since the uniqueness and creativity of the ad and not a negative impression such as the impression of being upset since the ad appears to interfere the internet user activity. Online advertising does not have a direct effect on internet users as consumers. However, research from Afzal and Khan (2015) discovered that purchases made by consumers are caused by a positive attitude towards advertising and the characteristics of the seen advertisements [39]. Online advertising is considered has an indirect effect on buying behavior on consumers.

Research from Nasir (2017) found that there was no difference between internet users who were busy and had little time with users who were relaxing [40]. The study found that internet users who hold a positive belief in online ad have a high level of search variation, and innovation compared to those who have a negative belief. Internet users who have both negative and positive belief in online ad still have a high risk of aversion. The Consumers responses that desired by advertisers are cognitive changes, attitudes and emotions of users towards the message conveyed by the ad. These changes include the ability to recognize and recall advertisements, brands, and products. Other outcomes that are also expected from advertising are activities and decisions such as coming to the seller's website, forming or changing attitudes towards advertisements, brands, mentioned products, sending emails to the advertiser, looking for information about products, and product purchases [41].

\section{B. Online Advertising Effectiveness for Internet Users}

Online advertising offers some advantages for consumers. Consumers who want to look for product references or find information before purchasing do not need to pay for magazines or newspapers. Consumers also receive useful information so they do not have to spend time searching for information about the product or service they want to buy [11]. Several studies have found that many internet users avoid online advertising because it is considered annoying [42], [43]. The study from Kelly, Kerr, and Drennan (2019) stated that avoidance towards advertisements by internet users occurred because it was not relevant to the interests and the 
messages was considered untrustworthy [42]. Another reason why internet users avoid online advertising is caused by negative experiences that have been experienced either by themselves or relatives regarding involvement in online advertising. Negative experiences that occur when a user clicks on an ad banner will make the user's computer exposed to a virus or misinformation that is misused by other parties [42].

Cho and Cheon (2004) in their journal explained several factors that cause users avoid the online advertising [43]. The first factor is that the internet is still considered as a medium that helps the user to finish their work performance and it is not intended for entertainment. When internet users only have a small amount of time to complete their tasks and work, online ad are considered very annoying. The second factor refers to data speed and access to the internet. Internet users are very concerned about data speed and when online ad appear, it are considered to slow down the data access as when downloading files.

There are 5 factors that contribute to the internet users' response attitudes towards online advertising [9]. The first factor is the advertising utility that refers to the value of advertisements that fit the consumer's needs. How informative and entertaining the ad is and how useful the ad is for making purchasing decisions. The second factor is indignity. Some internet users feel that online advertising insult and attack their value or culture. The third factor is trust. Consumers can trust online advertising to make purchasing decisions. Next there is the factor of price perception. Online advertising does not change the user's perception of the price of the product. The fourth factor is regulation. Internet users want the government not to interfere in online advertising regulations.

Consumer attitudes and beliefs are important determination of advertising effectiveness. Research from Wang et al. (2009) explained there are five factors that influence consumer attitudes and beliefs about online ad that consist of entertainment / entertainment, information search, credibility, economics and value corruption [44]. The study discovered that information seeking factor is the positive predictor of consumer attitudes and beliefs in online ad. Information seeking in this research refers to the assumption that online ad can provide needed information by consumers. The economy is also a positive predictive factor. The internet users who have attitudes and beliefs in online advertising will help improve economic development. Advertising is important in a business and makes a standard of living for consumers. Value corruption is also a positive predictor of consumer attitudes and beliefs about online advertising. When advertising does not attack consumer values, positive attitudes and beliefs about online ad will emerge. The study also found that the higher attitudes and consumer confidence in an online advertisement would increase ad clicks and purchases. Another study has found that the effectiveness of online advertising is also influenced by the culture that causes the reactions of each consumer differently depending on which culture the consumer tastes [45]. Internet users feel disturbed by marketing techniques such as e-mail. Users prefer to search for desired product information and prices offered [45].

The advertisements on a web also causes disadvantage on the web if the ad are considered disturbing.
The negative effects of advertising, involve the consequences of the quality of user experience on websites, that might arise are [41] :

1. May occur in the activities of reading, observing, and browsing with low quality due to disturbance,

\section{The information seeking might fail.}

3. The Internet Users may become tired and confused and will deal with cognitive processes that is going to increase.

4. Users may experience frustration, irritation, and might develop negative effects, emotions or moods with the honor of advertising.

5. Users may give a negative attitude to the website that shows ad, lead to a reduction in the duration of the visit, some changes and increase the negative WOM.

\section{CONCLUSION}

Observations on several journals showed that the effectiveness of online advertising could be seen from the click-through-rate (CTR). CTR is a measurement of the shortterm effectiveness of online advertising. CTR is also used as an online advertising payment method. There is another method of online advertising payment, it is pay-per-action. The effectiveness of online advertising for advertisers could be improved by setting some features in online advertising. Previous research found that the size of the ad separately did not affect the effectiveness of online advertising as seen from the CTR. However, if ad sizes are combined with interesting and concise advertising message content, it will increase the possibility of CTR for internet users. Ad content with video and images turns out to be more interesting than text. Advertising content that attacks the values of internet users will bring up negative attitudes from users. Therefore, advertisers should combine ad size as well as the content and form of messages created. The contents of the message should be short and interesting and not attack certain user's values. Internet advertising allows advertisers to know the user's demographic data so that advertiser could minimize messages that attack the values according to the demographic data. Advertisers may be able to create ad in the form of videos.

The effectiveness of online advertising depends on the objectives of each consumer in using the internet. Consumers with the goal to find information about a product / service before purchase will feel online advertising is useful with various conveniences than having to buy magazines and newspapers. On the contrary for consumers with the goal to use the internet to work and do their jobs, online advertising will be considered very disruptive and hinders the completion of tasks and work. Internet users will usually avoid these advertisements. Therefore, on consumer's point of view, advertisements that can provide short information and content relevant to the webpage where an ad is displayed will be very effective for advertisers and internet users. If advertisements appear to interfere the internet users activities, then this will harm both parties.

\section{REFERENCES}

[1] Y. Yin, K. E. Stecke, and D. Li, "The evolution of production systems from Industry 2.0 through Industry 4.0," Int. J. Prod. Res., vol. 56, no. 1-2, pp. 848-861, 2018.

[2] M. Lombard and J. Snyder-Duch, "Interactive Advertising and Presence," J. Interact. Advert., vol. 1, no. 2, pp. 56-65, 2013. 
[3] T. T. An Nguyen, C. P. Chang, and S. M. Yuan, "A Wi-Fi union mechanism for internet advertising reciprocal platform in microenterprises," Sensors (Switzerland), vol. 17, no. 7, 2017.

[4] A. M. Barreto, "Do users look at banner ads on Facebook?," J. Res. Interact. Mark., vol. 7, no. 2, pp. 119-139, 2013.

[5] A. P. J. I. I. (APJII), "Infografis: Penetrasi \& Perilaku Pengguna Internet Indonesia," 2017.

[6] Harry, "Nielsen: Belanja Iklan Digital di Bulan Agustus 2018 Mencapai Rp 1,3 Triliun," 2018. [Online]. Available: https://jakartakita.com/2018/12/14/nielsen-belanja-iklan-digital-dibulan-agustus-2018-mencapai-rp-13-triliun/.

[7] C. McNair, "Global Digital Users Update 2018tle," 2018. [Online]. Available: https://www.emarketer.com/content/global-digital-usersupdate-2018. [Accessed: 21-Mar-2019].

[8] B. Sheng, J. Gao, L. Chang, and S. Shim, "Online Advertising Taxonomy and Engineering Perspectives," no. March, pp. 1-33, 2013.

[9] A. E. Schlosser, S. Shavitt, and A. Kanfer, "Suvery of Internet Users' Attitude Toward Internet Advertising," J. Interact. Mark., vol. 13, no. 3, pp. 34-54, 1999.

[10] R. Palanisamy, "Impact of gender differences on online consumer characteristics on Web-based banner advertising effectiveness," $J$. Serv. Res., vol. 4, no. 2, pp. 45-74, 2004.

[11] D. S. Evans, "The Online Advertising Industry : Economies , Evolution , and Privacy," vol. 23, no. 3, pp. 37-60, 2019.

[12] J. Mohr, S. Sengupta, and S. Slater, Marketing of High-Technology Products and Innovations, 3rd ed. New Jersey: Pearson, 2010.

[13] A. Lambrecht and C. E. Tucker, "When does Retargeting Work? Information Specificity in Online Advertising," Ssrn, vol. 50, no. 5, pp. 561-576, 2011.

[14] S. M. Edwards, H. Li, and J. Lee, "Forced exposure and psychologica reactance: Antecedents and consequences of the Perceived Intrusiveness of Pop-Up Ads," J. Advert., vol. 31, no. 3, pp. 83-95, 2002

[15] F. Diao and S. S. Sundar, "Orienting response and memory for web advertisements: Exploring effects of pop-up window and animation,' Communic. Res., vol. 31, no. 5, pp. 537-567, 2004.

[16] T. Tavor, "Online Advertising Development and Their Economic Effectiveness," Aust. J. Bus. Manag. Res., vol. 1, no. 6, pp. 121-133, 2011

[17] S. C. Boerman, S. Kruikemeier, and F. J. Zuiderveen Borgesius, "Online Behavioral Advertising: A Literature Review and Research Agenda," J. Advert., vol. 46, no. 3, pp. 363-376, 2017.

[18] Y. Kim, "Consumer Response to Coupon Advertising," Int. J. Advert. vol. 14, no. 1, pp. 41-53, 1995.

[19] R. Breuer and M. Brettel, "Short- and Long-term Effects of Online Advertising: Differences between New and Existing Customers," $J$. Interact. Mark., vol. 26, no. 3, pp. 155-166, 2012.

[20] R. Sen, “Optimal Search Engine Marketing Strategy,” Int. J. Electron. Commer., vol. 10, no. 1, pp. 9-25, 2018

[21] D. Hussain and E. S. C. Rennes, "Online Video Advertisement Avoidance:," J. Appl. Bus. Res., vol. 30, no. 1, pp. 43-50, 2014.

[22] M. Pärssinen, M. Kotila, R. Cuevas, A. Phansalkar, and J. Manner, "Environmental impact assessment of online advertising," Environ. Impact Assess. Rev., vol. 73, no. September 2017, pp. 177-200, 2018.

[23] N. Karlsson, "Control problems in online advertising and benefits of randomized bidding strategies," Eur. J. Control, vol. 30, pp. 31-49, 2016.

[24] K. Windels and M. Stuhlfaut, "New Advertising Agency Roles in the Ever-Expanding Media Landscape,” J. Curr. Issues Res. Advert., vol. 39, no. 3, pp. 226-243, 2018.

[25] N. Mackenzie and S. Knipe, "Research dilemmas: Paradigms, methods and methodology," Issues Educ. Res., vol. 16, pp. 1-11, 2006.
[26] E. Karadağ, F. Bektas, N. Coğaltay, and M. Yalçın, "The effect of educational leadership on students' achievement: a meta-analysis study," Asia Pacific Education Review, vol. 16, no. 1. pp. 79-93, 2015.

[27] A. Pergelova, D. Prior, and J. Rialp, "Assessing Advertising Efficiency," J. Advert., vol. 39, no. 3, pp. 39-54, 2010.

[28] J. M. Jung, H. C. M. Hui, K. S. Min, and D. Martin, "Does telic/paratelic user mode matter on the effectiveness of interactive internet advertising? A reversal theory perspective," J. Bus. Res., vol. 67, no. 6, pp. 1303-1309, 2014.

[29] X. Drèze and F. X. Hussherr, "Internet advertising: Is anybody watching?," J. Interact. Mark., vol. 17, no. 4, pp. 8-23, 2003.

[30] Q.-H. Chen, S.-M. Yu, Z.-X. Guo, and Y.-B. Jia, "Estimating Ads" Click through Rate with Recurrent Neural Network," ITM Web Conf., vol. 7, p. 04001, 2016.

[31] M. Mahdian and K. Tomak, "Pay-per-Action Model for Online Advertising," in Proceeding of the 1st International workshop on Data Mining and Audience Intelligence for Advertising, 2007, pp. 1-6.

[32] H. Robinson, A. Wysocka, and C. Hand, "Internet advertising effectiveness," Int. J. Advert., vol. 26, no. 4, pp. 527-541, 2017.

[33] Y. L. Lin and Y. W. Chen, "Effects of ad types, positions, animation lengths, and exposure times on the click-through rate of animated online advertisings," Comput. Ind. Eng., vol. 57, no. 2, pp. 580-591, 2009.

[34] Y. C. Hsieh and K. H. Chen, "How different information types affect viewer's attention on internet advertising," Comput. Human Behav., vol. 27, no. 2, pp. 935-945, 2011.

[35] E. J. Newman, D. E. Stem, and D. E. Sprott, "Banner advertisement and Web site congruity effects on consumer Web site perceptions," Ind. Manag. Data Syst., vol. 104, no. 3, pp. 273-281, 2004.

[36] J. H. Schumann, F. V. Wangenheim, and N. Groene, "Targeted Online Advertising: Using Reciprocity Appeals to Increase Acceptance Among Users of Free Web Services," Ssrn, vol. 78, no. 1, pp. 59-75, 2013

[37] N. Hollis, "Ten years of learning on how online advertising builds brands," J. Advert. Res., vol. 45, no. 2, pp. 255-268, 2005.

[38] J. Peng, G. Zhang, S. Zhang, X. Dai, and J. Li, "Effects of online advertising on automobile sales," Manag. Decis., vol. 52, no. 5, pp. 834-851, 2014

[39] S. Afzal and J. R. Khan, "Impact of Online and Conventional Advertisement on Consumer Buying Behaviour of Branded Garments," Asian J. Manag. Sci. Educ., vol. 4, no. January, pp. 125135, 2015.

[40] V. A. Nasir, "Identification of Web User Segments Based on Beliefs about Online Ads," J. Internet Commer., vol. 16, no. 3, pp. 231-254, 2017.

[41] G. Brajnik and S. Gabrielli, "A review of online advertising effects on the user experience," Int. J. Hum. Comput. Interact., vol. 26, no. 10, pp. 971-997, 2010 .

[42] L. Kelly, G. Kerr, and J. Drennan, "Avoidance of Advertising in Social Networking Sites AVOIDANCE OF ADVERTISING IN SOCIAL NETWORKING SITES: THE TEENAGE PERSPECTIVE," vol. 2019, 2019.

[43] C. H. Cho and H. J. Cheon, "Why do people avoid advertising on the internet?," J. Advert., vol. 33, no. 4, pp. 89-97, 2004.

[44] Y. Wang, S. Sun, W. Lei, and M. Toncar, "Examining beliefs and attitudes toward online advertising among Chinese consumers," Direct Mark., vol. 3, no. 1, pp. 52-66, 2009.

[45] A. Spilker-Attig and M. Brettel, "Effectiveness of online advertising channels: A price-level-dependent analysis," New Dev. Online Mark., vol. 1376, pp. 165-182, 2013 